\title{
Designing of Fire Extinguisher Based on Sound Waves
}

\author{
Ritik Yadav, Ramiz Shirazi, Amit Choudhary, Sandeep Yadav, Rituraj Raghuvanshi
}

\begin{abstract}
The project titled Designing of Fire Extinguisher Based on Sound Waves is associated with new technique of fire extinguisher. Deals with the fire fighting operations with a quick response time. The purpose of sound wave extinguisher is to find out the range of frequency within which fire can be extinguished. It helps the fire fighter to fight the fire at early stage. Fire can be extinguished between $40 \mathrm{~Hz}$ to $60 \mathrm{~Hz}$ and the sound wave can extinguish the fire of all types of flames. The fire suppression needs to be done at the incipient stage where the heat and flame produced by the fire is at the minimum point. The expected outcome of the project will be, to counter the fire at its initial stage for better human safety and protection.

Keywords: Fire, Flame, Fire Extinguishers, Chemical extinguisher, Residue, Sound Waves, Sound Wave Fire Extinguisher, Fire extinguishing effect, Dousing Fire.
\end{abstract}

\section{INTRODUCTION}

Fire extinguisher is an equipment primarily designed for fire fighting operations. Extinguishers are generally used by fire departments and also to fight the fire at its growth stage. The primary purpose of fire extinguisher is its easy operation, easy to handle, and leaves no residue after usage, and doesn't harm the environment. A sound wave extinguisher will extinguish the flame of all types and the frequency range can be measured between $40 \mathrm{~Hz}$ to $60 \mathrm{~Hz}$. Further the waves can be classified into two groups which are mentioned as under:

1. Longitudinal Wave- also known as compression wave which provides compression and rarefaction when moving in the same direction or opposite. The displacement of the medium can be vice- versa.

2. Transverse Wave- known as moving wave and has number of oscillations occurring perpendicular from the energy where it is transferred. One of the best reasons is light. Medium of displacement is perpendicular to the wave propagation of direction.

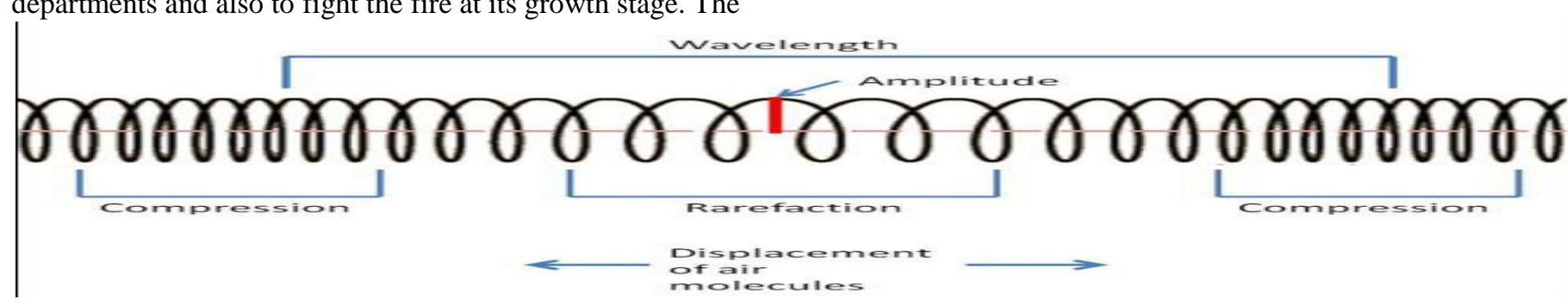

Figure 1.1 : Longitudinal Waves

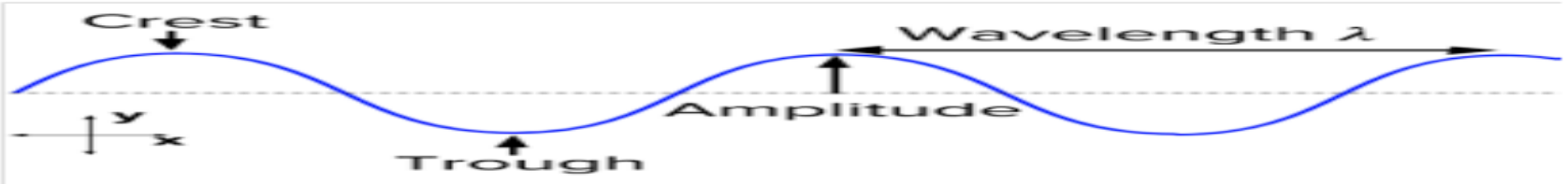

Figure 1.2 : Transverse Wave

Fire

The threeimportant elements that formsthe 'Fire Triangle' i.e. Heat, Fueland Oxygen. As fire is primarily anexothermic chemical reaction i.e. the rapid oxidation of the available fuel in the presence of heat source and gives

Revised Manuscript Received on April 25, 2020.

* Correspondence Author

Mr. Ritik Yadav*, (B.Tech Scholar), Fire Technology \& Safety Engineering mMedi - Caps University, Indore, India

Mr. Ramiz Shirazi (B.Tech Scholar), Fire Technology \& Safety Engineering, Medi - Caps University, Indore, India

Dr. Sandeep Yadav (Ph.D). (Mechanical Engineering), Assistant Professor, Department of Fire Technology \& Safety Engineering, MediCaps University, Indore, India

Mr. Rituraj Raghuvanshi (M.Tech) (Industrial Safety Engineering), Assistant Professor, Department of Fire Technology \& Safety Engineering, Medi-Caps University, Indore, India

Mr. Amit Choudhary, (B.Tech Scholar), Fire Technology \& Safety Engineering, Medi - Caps University, Indore, India.

(C) The Authors. Published by Blue Eyes Intelligence Engineering and Sciences Publication (BEIESP). This is an open access article under the CC BY-NC-ND license (http://creativecommons.org/licenses/by-nc-nd/4.0/) by-products such as: - heat and light energy sensationand removing one or more of these three elements will extinguish the flame/fire.

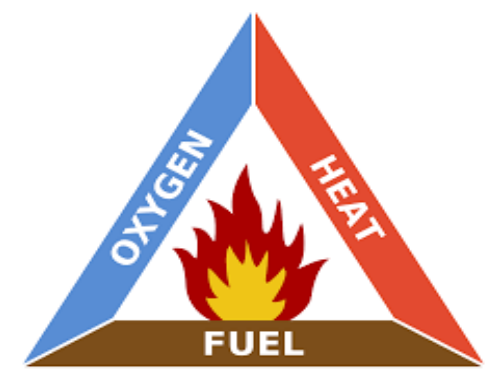

Figure 1.3: Fire Triangle

Published By:

Blue Eyes Intelligence Engineering \& Sciences Publication 


\section{Designing of Fire Extinguisher Based on Sound Waves}

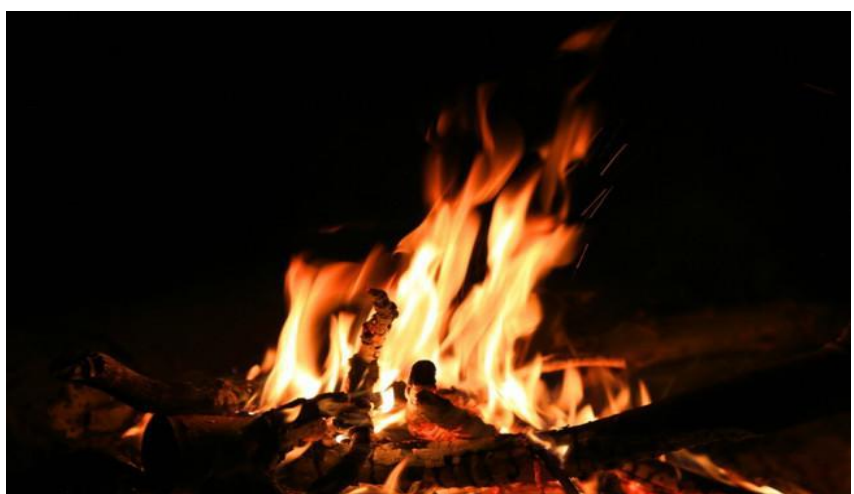

Figure 1.4: Fire

\section{Flame}

A flame is the visible, gaseous part of a fire. It is caused by a highlyexothermicreaction taking place in a thinzone.

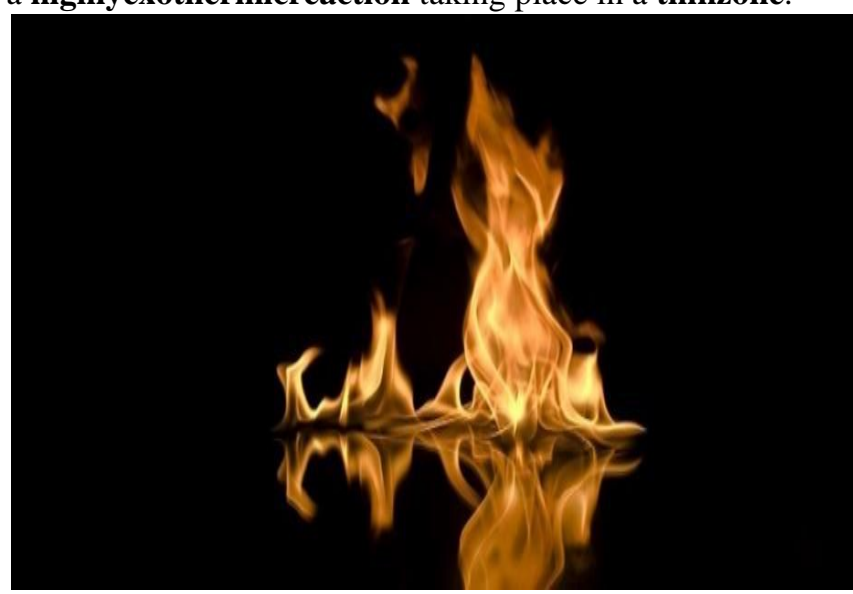

Figure 1.5: Flame

\section{Fire Extinguishing Methods}

The principleof fire extinction states that a fire will be doused if one of the three elements is removed, and this can be done using three different approaches. They are: -

Cooling (Cooling the Burning Material)

Starving (Removing Fuel from the Fire)

Smothering (Excluding Oxygen from the Fire).

Types of Fire Class A Fire which includes solid materials like wood, paper, plastic, rubber etc.

Class B Fire containing flammable liquids.

Class C Fire involves gaseous substances.

Class D contains combustible metals like aluminium, zinc, sodium, potassium etc.

\section{LITERATURE REVIEW}

The new idea of extinguishing the fire is important. Accidents occurred by fire are dangerous and life threatening. Due to increase of danger to environment possible measures to be taken to overcome it. So the recent technique will help in extinguishing the fire and as well as protecting the environment also. The other thing is the accident caused in space, so avoid the use of extinguisher there. Sound wave extinguisher is the equipment by which fire can be extinguished. For fire extinguishing many researches can be possible and analyzing which sound frequency will give good result is necessary. As far as flame extinguishment is concern the vibration may be at high- and low-levels when coupled with high air flow velocity cause disruptions in the air-fuel ratio at the flame boundary which leads to diminishing of the boundary. Technology in fire fighting has short comings like toxic to humans and leaves residues for DCP cylinder while water based extinguishers freezes in cold and conducts electricity. Sound wave extinguisher could be one of the potential alternatives as fire extinguishers.

\section{METHODOLOGY}

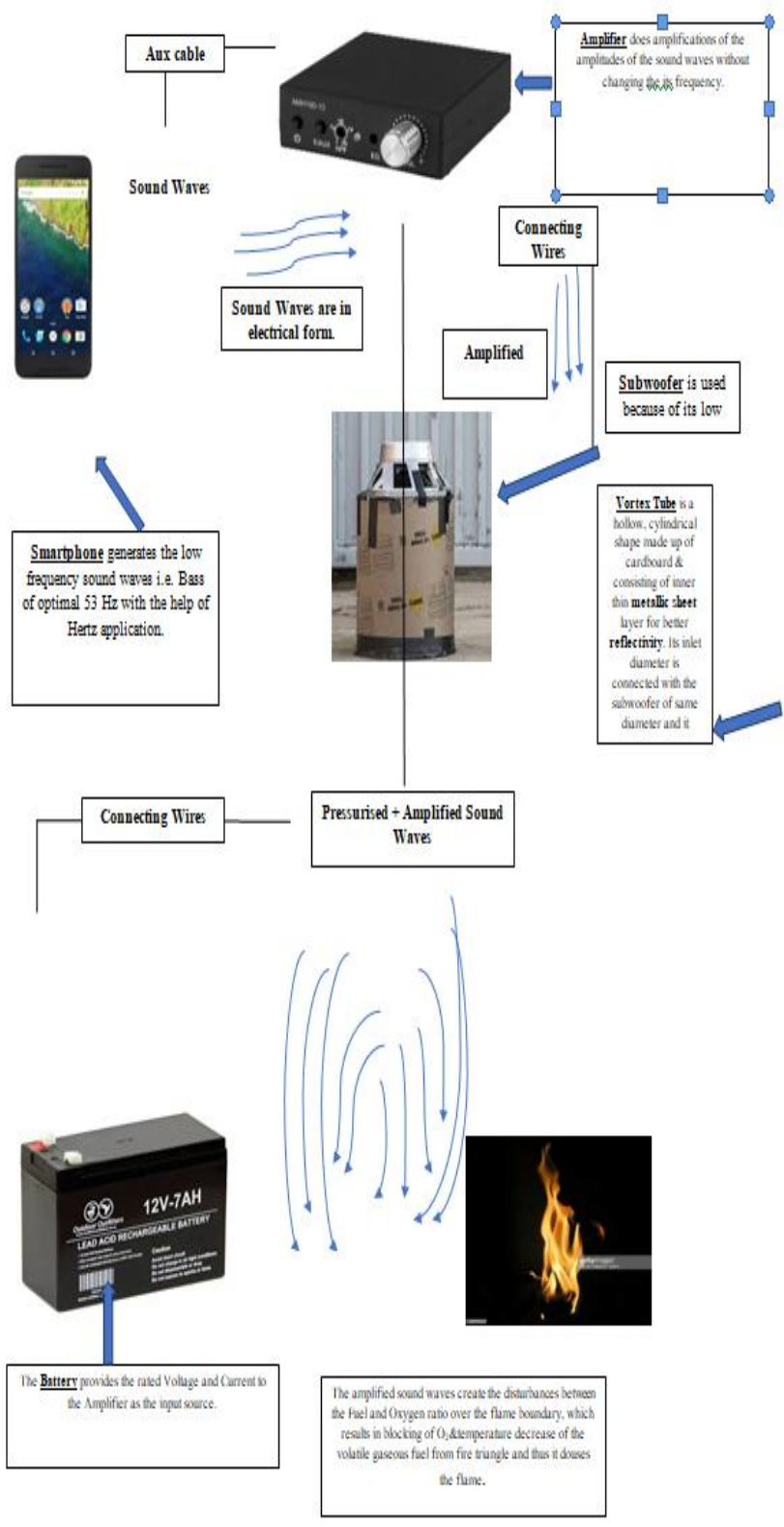

Sound Waves

\section{Problem Statement}

The limitations are covered as under : -

- Using Dry Chemical Powder base fire extinguisher releases toxics harmful for humans and leaves residue.

- $\quad$ Using Water type fire extinguisher may freezes in cold climates and has electricity.

- Water type fire extinguisher causes corrosion.

Published By:

Blue Eyes Intelligence Engineering

\& Sciences Publication

(C) Copyright: All rights reserved.

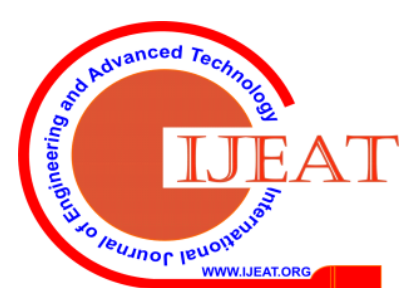


- Using $\mathrm{CO}_{2}$ fire extinguisher can cause coldburn on hand, if properly not handled.

Using Sound Waves with a certain optimal frequency as a fire extinguisher can overcome the above-mentioned drawbacks such as cold burn, leaving any residues and toxic materials.

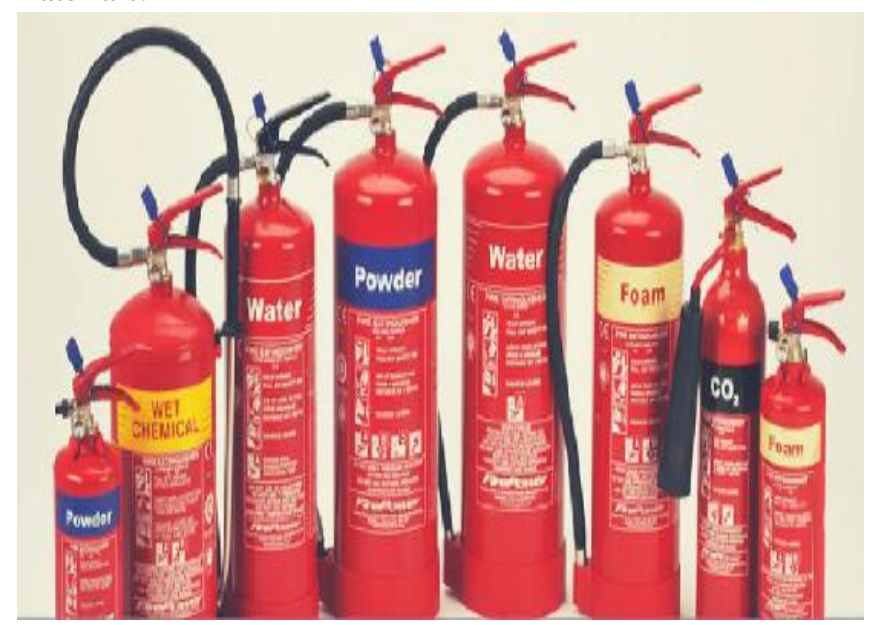

Figure 1.7: Standard Fire Extinguishers

Objectives: -

(a) To check the frequency range used to extinguish flame.

(b) To identify an optimal range of frequencies.

Working Principle

This concept teaches the physics, engineering and electronics approach so as to suppress a flame. Firstly, to get the knowledge of acoustical properties of sound waves which are longitudinal waves that moves backward and forward creating vibrating motion, as a result of which molecules moves away from the flame. Another is Ideal Gas which states that $(\mathrm{PV}=\mathrm{nRT})$ helps in suppressing a flame. So when pressure is exerted at the flame source it will get decreased and temperature will also get decreased of the flame.

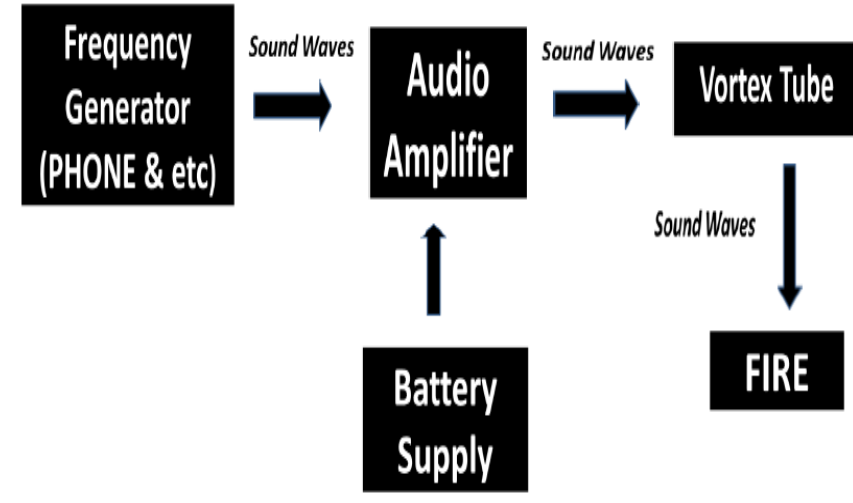

Figure 1.8: Flow Chart

Equipment Required: -

\section{Hardware}

- 100-Watt Subwoofer

- 500-Watt Amplifier

- Vortex tube (converging)

- 12 V Battery.

Software

- A Frequency Generator Application

\section{EXPERIMENT \& RESULT}
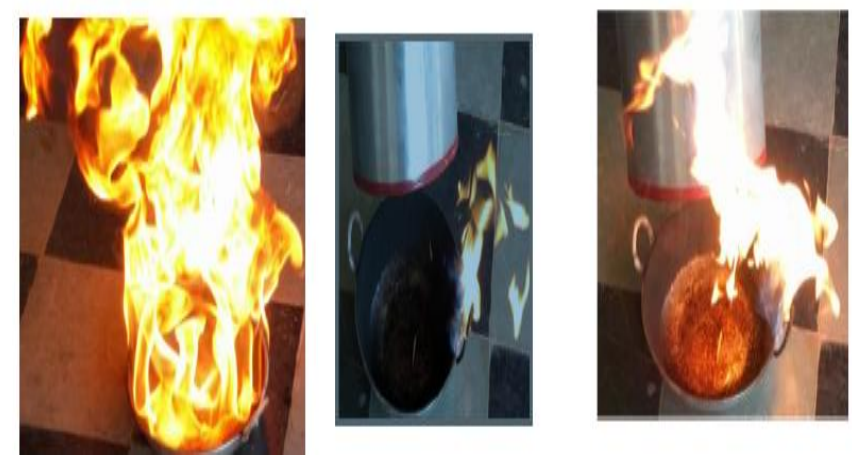

Figure 1.9: Testing of Sound Wave Fire Extinguisher Testing of the Portable Sound Wave Fire Extinguisher on Liquid Fire.

Table 1.1: Frequency-Time Table of the Experiment performed

\begin{tabular}{|l|l|l|l|l|l|l|l|l|l|l|l|l|l|}
\hline Time & 1.8 & 1.4 & 1.2 & 1 & 0.8 & 0.6 & 0.8 & 1 & 1.2 & 1.4 & 1.6 & 1.8 & 2 \\
\hline Frequency & 48 & 49 & 50 & 51 & 52 & 53 & 54 & 55 & 56 & 57 & 58 & 59 & 60 \\
\hline
\end{tabular}

Graph represents the variation of Time with Frequency of Sound Wave Fire Extinguisher extinguishing a flame/fire

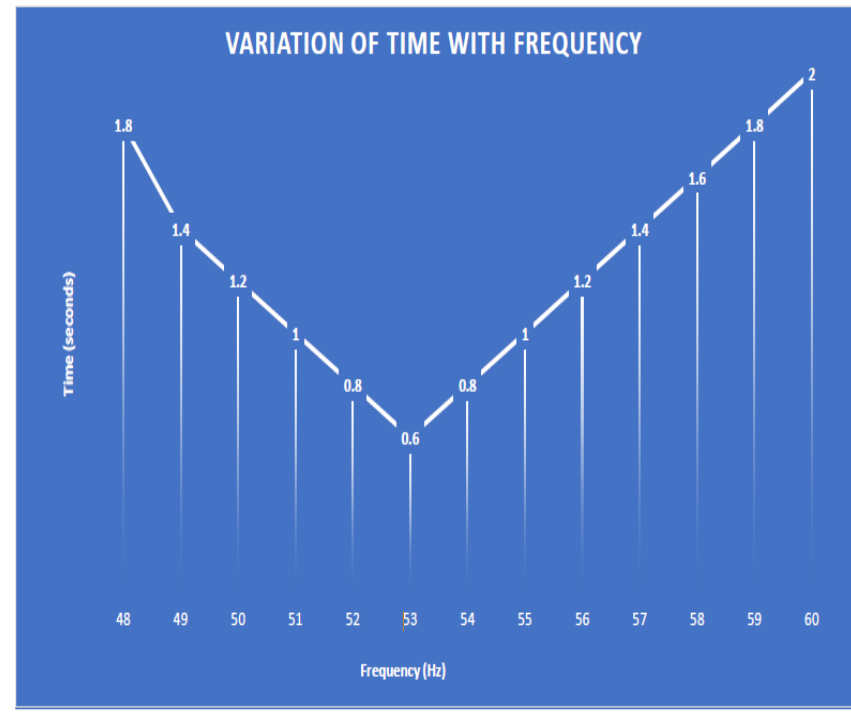

The vortex tube necessary to be included in the construction of this experiment has the following dimensions for optimization of extinguishing effect: Length is $300 \mathrm{~mm}$ and outlet diameter is $100 \mathrm{~mm}$. The optimal frequency is found to be between $51-55 \mathrm{~Hz}$.

\section{CONCLUSION}

Overall the design and improvisation of sound wave extinguisher has been done successfully. All the actions which has to be performed by extinguishers are working properly. Sound wave extinguisher with these modifications will be a new success in terms of safety as well as fire fighting and rescue operations. Based on the experiment result obtained it can be seen that the sound wave can extinguish flames.

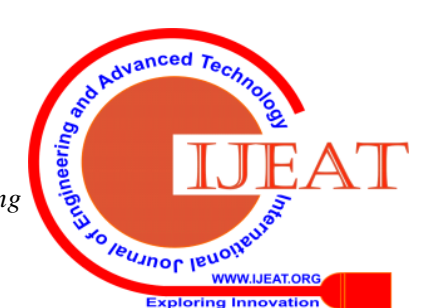


The optimal frequency range at which the flame can be suppressed is between 51-55 Hz.

\section{REFERENCES}

1. Accident Prevention Manual for Industrial Operations, National Safety Council, Chicago, Illinois.

2. NFPA Fire Protection Manual (16 volumes), USA.

3. Fire Protection Manual, Factory Manual Systems, HMSO, London.

4. Fire Protection Guide on Hazardous Materials, National Fire Protection, USA.

5. A handbook of Fire Technology, R.S. Gupta, Orient Longman Ltd., Mumbai.

6. Dust Explosions and Fires, K.N. Palmer, Chapman and Hall, London.

7. .Fuel and Combustion, Sharma, Tata McGraw Hill, Delhi.

8. Smoke Control in Fire Safety Design, Butcher and Parnell, E \& FN Spon Ltd., London.

9. .Rules for Segregation, Tariff Advisory Committee, Bombay Regional Committee, Bombay.

10. .Loss Prevention in the Process Industries, Frank P. Lees, Butterworth.

11. .Major Hazard Control, a practical manual, ILO, Geneva.

12. The Factories Act \& Rules.

13. Industrial Fire Protection Handbook. R.Craig Schroll

\section{AUTHORS PROFILE}

Mr. Ritik Yadav (B.Tech Scholar) ,Fire Technology \& Safety Engineering mMedi - Caps University, Indore, India

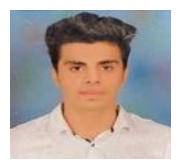

Mr. Ramiz Shirazi (B.Tech Scholar), Fire Technology \& Safety Engineering, Medi - Caps University, Indore, India

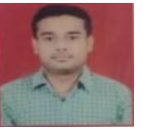

Dr. Sandeep Yadav (Ph.D). (Mechanical Engineering), Assistant Professor, Department of Fire Technology \& Safety Engineering, Medi-Caps University, Indore, India

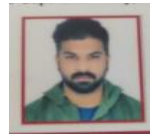

Mr. Rituraj Raghuvanshi (M.Tech) (Industrial Safety Engineering), Assistant Professor, Department of Fire Technology \& Safety Engineering, Medi-Caps University, Indore, India.

Mr. Amit Choudhary, (B.Tech Scholar), Fire Technology \& Safety Engineering, Medi - Caps University, Indore, India

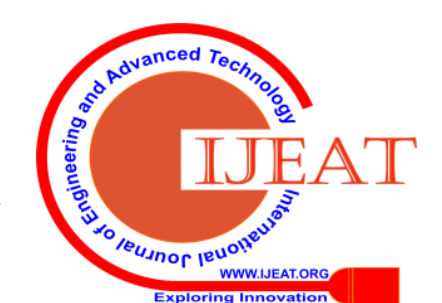

